\title{
STUDIES ON RESIDENT STRAINS OF INTESTINAL E. COLI AMONG INFANTS IN INFANT-HOME
}

\author{
BUNYA NAKAMURA*, MASAHIRO KOJIMA and MITSURU OSANO \\ Department of Pediatrics, School of Medicine, \\ Keio University
}

(Received on January 16, 1959)

Although there has recently been much progress made in the pediatric field, infantile diarrhea is still among one of the important problems especially in those of the bottle fed babies. Not only do the bottle babies have enteral diarrhea by pathogenic organism, but they are susceptible to parenteral diarrhea, which leads to believe that there would be, as it has been said, a strict relationship between the infections and the intestinal flora of infants.

Lact. bifidus, in general, keeps the symbiosis with the host as a normal intestinal flora of the breast babies and is considered to have the protective role, in some way, against the enteral infections.

On the other hand, $E$. coli has recently been proved to be a normal intestinal flora of the bottle babies, having symbiosis with those infants. Namely, there are antigenetically at least one to several types of the strains for a certain period having symbiosis with the host as a resident strain and it is observed to give its place to other strains owing to many factors such as diet, environment, infection, diarrhea, etc.

It is of interest to follow the resident strains of intestinal $E$. coli in the infants as they grow and to observe the effect of the bacterial or viral infection, either enteral or parenteral, and many other stresses on this symbiosis with the host.

In following the persistence of the resident strains for a period of over two years, some interesting results have been obtained. Since infantile diarrhea is frequently due to parenteral infections, an attempt was made to prove the effects of experimental parenteral infection on the persistence of the resident strains. Vaccination against small pox and $B C G$ vaccination were used as experimental viral and bacterial infections, respectively. The effects of other stress, such as an inoculation of pertussis vaccine and exposing the body during sleep, upon the residency of the intestinal $E$. coli have also been observed.

To understand the problem of the persistency of the particular intestinal $E$. coli

\footnotetext{
* Professor of Pediatrics.
} 
in the particular infant, a former resident strain was orally given in case whose stool specimen revealed no growth of $E$. coli on plate for some five months, in an attempt artificially to reestablish the residency.

The influence of oral administration of Lact. bifidus for a long period on the resident strain was also observed.

\section{METHOD OF STUDIES}

A. Subject and duration of observation

Seven bottle babies, including two sets of identical twins, male and female, respectively, in an infant-home of Tokyo were chosen for this study.

\begin{tabular}{c|cc} 
Subject & $\begin{array}{c}\text { Age at initial observation } \\
\text { months }\end{array}$ & $\begin{array}{c}\text { Duration } \\
\text { months }\end{array}$ \\
A & 8 & 18 \\
B & 8 & 18 \\
C & 7 & 26 \\
D & 2 & 11 \\
E & 2 & 11 \\
F & 4 & 10 \\
G & 2 & 10
\end{tabular}

B. Culture medium and interval of observation

At the beginning BTB or EMB medium was used and later was switched to Tergitol-7 agar of Chapman as a selective medium for $E$. coli.

$\begin{array}{lr}\text { Tergitol-7 Agar } & \\ \text { Proteose Peptone No. 3 Difco } & 5.0 \mathrm{~g} \\ \text { Bacto Yeast Extract, Difco } & 3.0 \mathrm{~g} \\ \text { Lactose } & 10.0 \mathrm{~g} \\ \text { Agar } & 15.0 \mathrm{~g} \\ \text { Aq. } & 1000.0 \mathrm{ml}\end{array}$

$\mathrm{pH}$ was adjusted to 6.9 and $0.1 \mathrm{ml}$ of Tergitol 7 and $2.5 \mathrm{ml}$ of $1 \%$ BTB solution were added.

$40 \mathrm{mg}$ of triphenyltetrazolium chloride (TTC) was added just before pouring in one litre of Tergitol-7 agar.

Initially stool culture was taken every day for a week, then twice a week. In the case of experimental infection or stress daily culture was taken for a week to ten days.

C. Preparation of anti-O serum

1. Anti-O serum of individual strain 
Each strain of $E$. coli selected by IMVC test was segregated by biological reaction and its appearence of colony, and the strains having the same characteristic were considered belonging to the same genus. The strains which appeared frequently and prominently were selected as antigen and rabbits were immunized with these. Broth of 18-hour culture of those $E$. coli was heated for two and a half hours at $100^{\circ} \mathrm{C}$. These heat killed antigens were inoculated intravenously in five devided doses of $0.5,1.0,2.0,4.0$, and $4.0 \mathrm{ml}$ at intervals of four to five days. Serum having agglutinin titer of over $1: 800$ in one two weeks was utilized.

2. Anti O 1-134 sera of Kauffmann

In order to identify the many strains which appeared transiently among the resident strains, anti $O$ sera to standard strains of Kauffmann were necessary. $2 \mathrm{ml}$ of $2 \%$ potassium chromate and $2 \mathrm{ml}$ of formaline were added to the heat killed $\left(2^{1} / 2\right.$ hours at $\left.100^{\circ} \mathrm{C}\right)$ antigen and was chromnized for three days at $37^{\circ} \mathrm{C}$. After washing twice with normal saline a chromnized vaccine was inoculated intravenously and a serum having agglutinin titer of over 1:800 within one to two weeks was used.

3. Determination of isolated strain

Using a mixed anti $O$ serum by each having agglutinin titer of $1: 100$, the preliminary agglutination test was performed. Strains which gave positive reaction to the mixed anti $O$ serum were tested against each anti $O$ serum component and determined quantitatively. Absorption test was then performed in some of them.

In those strains having positive reactions to anti $O$ sera prepared by method 1 , it is reasonable to believe that determination of $O$ antigen of these sera with standard strains means serologic typing of each strain. The total number of strains tested was 1459 , of which 422 strains were determined belonging to the standard strain of $01-0134$.

\section{RESULTS}

\section{A. Persistence of E. coli}

Case A (Fig. 1) : A 22 and $\mathrm{O} 4$ strains persisted predominently while other strains were less persistent at first. Because of hospital situation no observation was made for a month in May, 1956. A 22 strain persisted for $3^{1 / 2}$ months and $\mathrm{O} 4$ strain for 4 months. In the following six months, from May to October, there were short periods of persistences in these resident strains. From November, 1956 to April, 1957, there were comparatively long periods of persistences in the resident strains, C 169 and O 114, as observed in the previous year.

Case $\mathrm{B}$ (Fig. 2): The $\mathrm{O} 4$ strain persisted for four months in this case also and was followed by short period of persistency of many strains from May to 


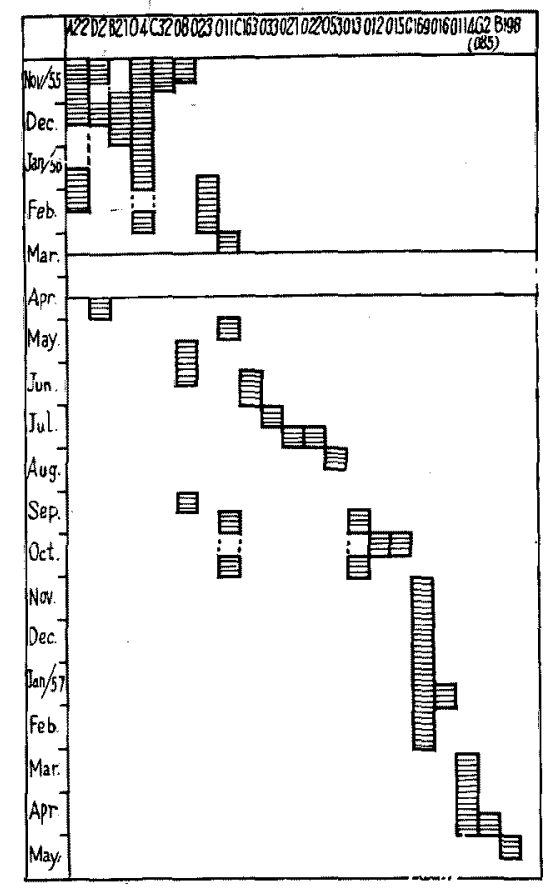

Fig. 1 Result on case A.

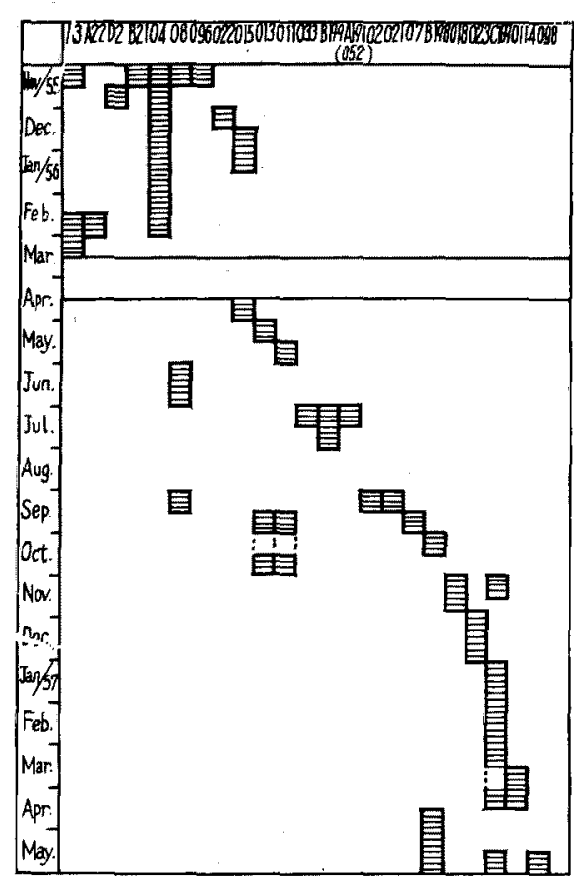

Fig. 2 Result on case B.

October as in Case $\mathrm{A}$ of his brother. $\mathrm{A}$ and $\mathrm{B}$ are identical twins and were boarded in adjacent beds and were cared for by the same nurse. In other word, they were under the same genetic and environmental factors. There, however, was no definite similarity in the case of these twins, although there was a resemblance in regard to type of strain and the time of appearance or disappearance.

Case C (Fig. 3): This was a case having primary pulmonary tuberculosis and was treated with daily INH p.o. and streptomycin I. M. twice a week. No effect on the resident strain was found in discontinuance of streptomycin or daily INH. O 4 strain persisted for seven months and was followed by strains having short persistency from June to October.

In this particular case no $E$. coli colony had been grown on plate for approximately five months from December, 1956 to May, 1957. There was no conceivable factor which might precipitate the disappearance or reappearance of $E$. coli and there was no clinical symptom in either circumstance. For this five-month period she had an unusual intestinal flora composed mostly of enterococci associated with some Lact. bifidus, but no $E$. coli. After reappearance of $E$. coli, namely, from May to October, there were various strains having short persistency.

Case D (Fig. 4) : O15 strain persisted for five months, subsequently, C 32 


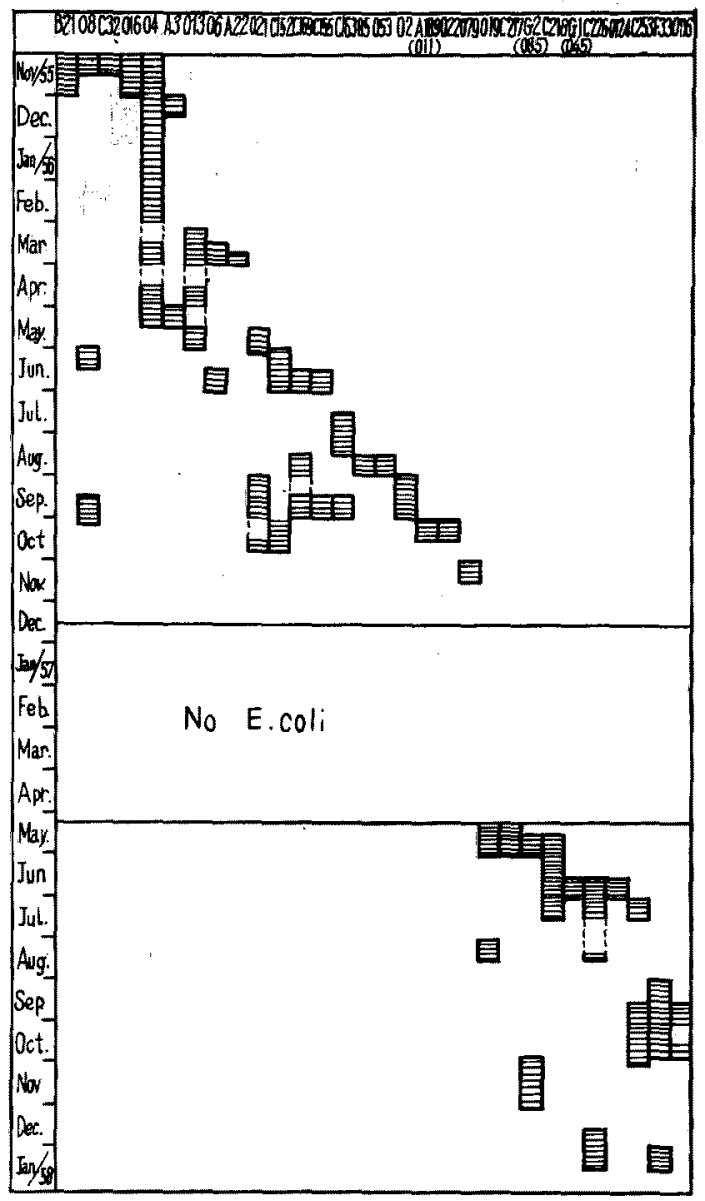

Fig. 3 Result on case C.

strain for several months.

Case E (Fig. 5) was nursed under the same environmental factors as her twin sister in D. Resident strain of this case, however, was $\mathrm{O} 4$ for the first two and a half months and $\mathrm{O} 15$ and $\mathrm{C} 32$ strains which persisted in her sister were isolated only occasionally. Again there was no distinct similarity in the resident strains in these identical twins despite their being under the same environmental conditions. There were also short periods of persistency is resident strains in this case from May to October, and she had several occasions of diarrhea during this period.

B. Effect of infections or other diseases and medical treatment on resident strain Case A (Fig. 1) had five occasions of common cold and was treated with penicillin and sulfa drugs. There were some effects on the resident strains in 3 of 


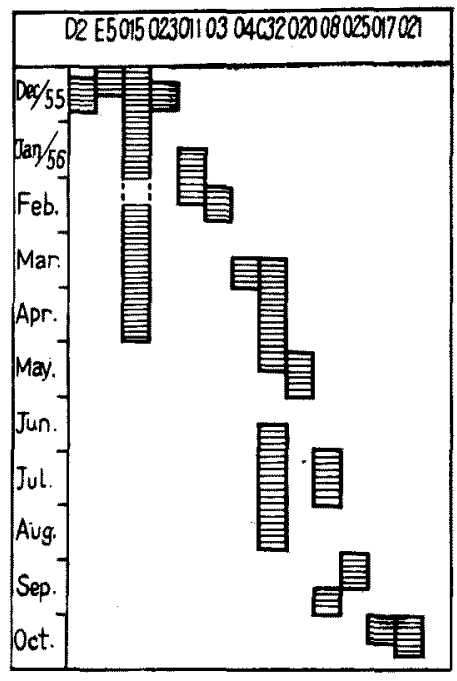

Fig. 4 Result on case D.

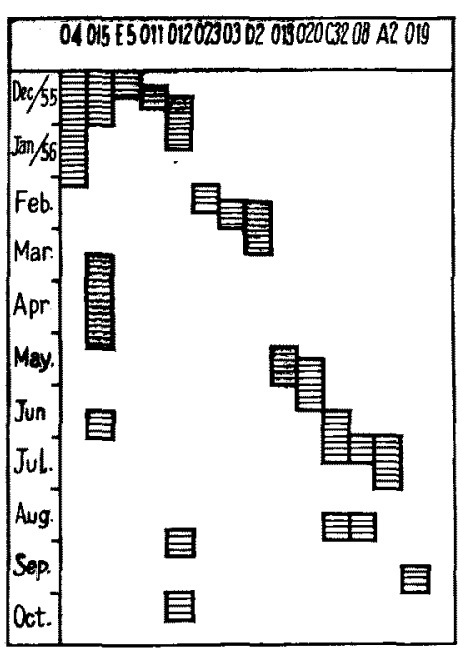

Fig. 5 Result on case E.

5 occasions $(11 / 16 / 55,12 / 29 / 55,1 / 20 / 56)$. He had a mild case of chicken pox on $1 / 26 / 57$ but no effect was found on resident strain, C 169.

Case B (Fig. 2) : Although he had 10 occasions of common cold there was no effect on the resident strains.

Case C (Fig. 3) : On 5 of 12 occasions of common cold treated with penicillin and sulfa drugs there were transitions of resident strains (2/28/56, 4/6/56, 10/1/56, $7 / 12 / 57,12 / 1 / 57)$. She was susceptible to skin infections, such as secondary infection of eczema or frunclosis, however, those skin infections resulted in no change of resident strains. Surgical scarlet fever manifested on 6/22/57 proved not effective on resident strains, C 218 and C 226.

Case D (Fig. 4) : On 3 of 9 occasions of common cold, transitions of resident strains were found $(12 / 8 / 55,1 / 24 / 56,7 / 2 / 56)$. Having bronchitis on $8 / 1 / 56,08$ strain subsequently disappeared.

Case E (Fig. 5): No effect on resident strain was proved although she had 9 occasions of common cold. In case of bronchitis on $6 / 27 / 56$ a resident strain $\mathrm{O} 15$ was replaced by $\mathrm{O} 8$ and $\mathrm{A} 2$ strains.

C. Relationship between diarrhea and change of resident strain

Case A (Fig. 1): On two of four occasions of diarrhea of relatively long duration, there were transitions of resident strains $(6 / 1-10 / 56,3 / 5-12 / 57)$. He had many occasions of bloody stools for some two months, at age of 18 months, and was proved to have amebic dysentery. During this period there was no steady residency of $E$. coli. 
Case B (Fig. 2) : On 3 of 8 occasions of diarrhea, transitions of resident strains were found $(10 / 25-28 / 56,11 / 21 / 56,12 / 29 / 56)$. At age of 18 months he also had occasional bloody stools for some two months. Although it was failed to prove Endamoeba histolytica, he had no steady resident strain during this period.

Case C (Fig. 3): On 3 of 6 occasions of diarrhea of relatively long duration, there were transitions of resident strains $(11 / 28-12 / 3 / 55,7 / 28 / 57,10 / 29 / 57)$.

There was a mild epidemic of pathogenic $E$. coli $O 55$ in this infant-home in October, 1956. Several colonies of $O 55$ strain were grown on plate on 10/8/56, however no clinical symptoms or change of resident strain was observed. In an attempt of clearing $O 55$ strain in the infant-home Colistin was given orally for three days to all the babies from 10/21/56. Administering daily Colistin of $300,000 \mathrm{u}$. for three days in this case, $\mathrm{C} 152$ strain was replaced by $\mathrm{O} 79$ strain.

Case D (Fig. 4): On one of two occasions of diarrhea, transition of resident strain was found $(5 / 1 / 56)$. Although a pure culture of $\mathrm{O} 55$ strain was obtained on one occasion during the epidemic, no clinical symptoms or effect on resident strain was found.

It is quite interesting to find the fact that in this epidemic pathogenic $E$. coli $\mathrm{O} 55$ did not take the place of the resident strain and the infant did not manifest any clinical symptoms, as it has been generally thought. However this was a mild case of epidemic and most of the affected infants had no or little symptoms. From these clinical points of view these discrepancies would be explained by a difference of pathogenicity of this $\mathrm{O} 55$ strain.

Case E (Fig. 5): Two of four occasions of diarrhea of relatively long duration led to transition of resident strains $(1 / 26-30 / 56,2 / 5-12 / 56)$. No O 55 strain was isolated in this case during the epidemic.

D. Effects of diet, excursions and removal of infants on resident strains

Case A (Fig. 1): With the first feeding of vegetable on 2/3/56 a resident strain $\mathrm{O} 4$ temporarily disappeared. After removal of the infant to another infanthome, O 11 strain was replaced by $\mathrm{O} 8$ strain without manifesting clinical symptoms.

Case B (Fig. 2) : The first feeding of vegetable on $2 / 3 / 56$ resulted in no transition of resident strain 04 . After removal of the infant to another infant-home the resident strain $\mathrm{O} 11$ was replaced by the $\mathrm{O} 8$ strain.

Case C (Fig. 3) : The first feeding of vegetable resulted in appearance of the O 6 strain. On two occasions of excursions to the U.S. Army Camp, there were transitions of resident strains (10/19/57, 12/21/57). Although these were just a half day's outing, it is interesting to find such an effect on the resident strains after the infant had eaten different kinds of foods and has been in contact with many different 
persons.

Case D (Fig. 4) : Addition of cereal in formula and introduction of vegetable had effects on the resident strains (12/29/55, 8/27/56).

Case $\mathrm{E}$ (Fig. 5) : Addition of cereal in formula and introduction of vegetable had effects on the resident strains, as seen in case D $(12 / 29 / 55,8 / 27 / 56)$.

E. Effect of vaccination against small pox on the resident strain

Case $B$ was vaccinated by scratch method on $1 / 24 / 57$. Two days after vaccination he had a mild case of chicken pox which proved not effective on resident strain, C 169. However there was less growth of $E$. coli on plate for three days from the third day of vaccination (Figs. 2, 6).

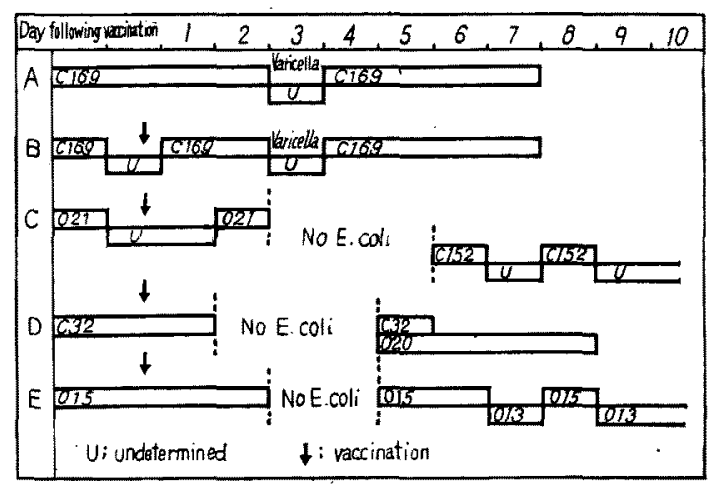

Fig. 6 Effect of vaccination on resident strains.

Case $C$ was vaccinated by multiple pressure method on $5 / 30 / 56$. There was no growth of $E$. coli on plate for three days from the third day of vaccination and when $E$. coli reappeared on the plate, resident strain $\mathrm{O} 13$ and $\mathrm{O} 21$ were replaced by the $\mathrm{O} 8$ and $\mathrm{C} 152$ strains (Figs. 3, 6).

Case D: From the second day of vaccination on $5 / 8 / 56$ there was no growth of $E$. coli on the plate for three days and the resident strain $\mathrm{C} 32$ disappeared (Figs. 4, 6).

Case $E$ : From the third day of vaccination on $5 / 8 / 56$ there was no growth of $E$. coli on the plate, and when the $E$. coli reappeared the resident strain $O 15$ was replaced by the $\mathrm{O} 13$ strain (Figs. 5,6 ).

Details of these data were shown in Fig. 6. There was a short period of little or no growth of $E$. coli on the plate from the second or third day of vaccination accompanied by transition of resident strain. Temporary disappearance of the resident strains or other $E$. coli after vaccination suggests the lability of the intestinal flora following this procedure. To confirm this phenomenon, 15 bottle babies were 
subjected to the same study. As seen in Fig. 7, eight of fifteen cases temporarily had little or no growth of $E$. coli on the plate after vaccination, and a certain effect

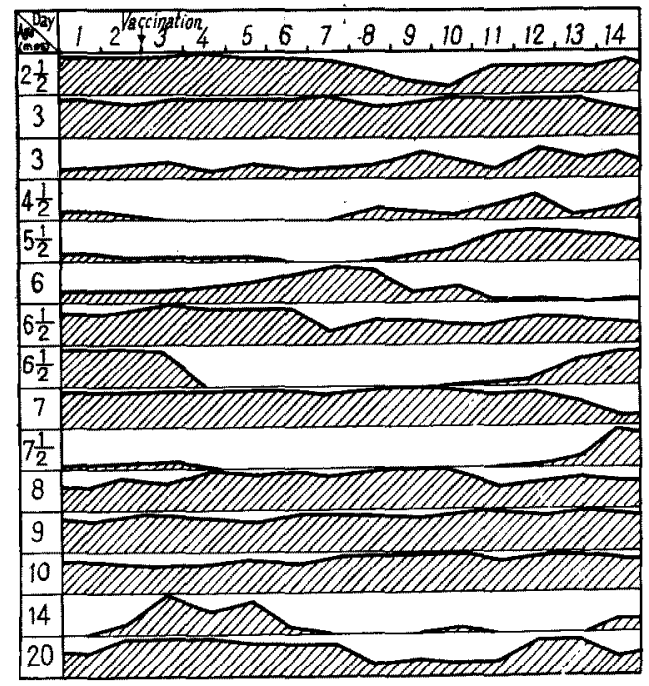

Fig. 7 Growth pattern of intestinal E. coli following vaccination.

of parenteral viral infection on the symbiosis of the intestinal flora of $E$. coli and the host was suggested.

F. Effects of $B C G$ and pertussis vaccination on the resident strains

Case $B$ was inoculated with pertussis vaccine on $1 / 13 / 57$ without effect on resident strain (Fig. 2).

Case D was inoculated with $\mathrm{BCG}$ vaccine as an experimental bacterial infection on 6/15/56 and reappearance of the $\mathrm{C} 32$ strain was found (Fig. 4).

Case $E$ also received BCG vaccination on $6 / 15 / 56$ which was followed by disappearance of $\mathrm{O} 20$, appearance of $\mathrm{O} 32$ and reappearance of $\mathrm{O} 15$ strain.

These results suggest that parenteral bacterial infection may also induce an effect on the symbiosis of the intestinal flora of E.coli and the host.

G. Effect of a former resident strain

As mentioned above, case $C$ was a particular case whose stool specimen became free of $E$. coli on the plate at the age of 18 months without probable cause or clinical symptoms. After some five months her stool specimen returned to positive for $E$. coli without causative factors or clinical symptoms. In this "five-monthperiod " repeated stool cultures, either aerobic or anaerobic on various culture media, such as BTB, EMB, agar plate or blood agar, revealed predominance of enterococci 
accompanied by some Lact. bifidus, but no $E$. coli.

Many attempts to establish artificially a new resident strain expelling the individual strains were reported to have been failures. In this particular instance we incidentally had a case in which the intestine was presumably free of $E$. coli. If in a new born infant the first arrived $E$. coli strain into the $E$. coli free intestine persists, we may expect that a strain given orally in this particular case would also persist. With respect to the persistency of $E$. coli, a former resident strain would be more easily reestablished than other strains of random selection.

In case $\mathrm{C}$ a slant culture of $\mathrm{C} 163$ strain for 24 hours was orally given at the age of 17 months. From the day after administration, the $\mathrm{C} 169$ strain appeared on the plate as a pure culture up to the fourth day, followed by a gradual decrease in growth and returned to previous $E$. coli free state in a week. Repeated stool

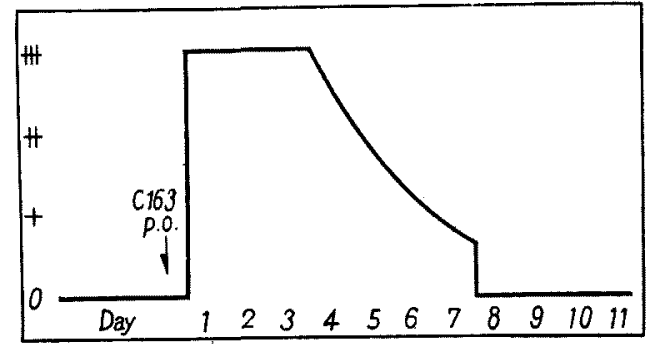

Fig. 8 Growth curve of C 163 strain.

cultures, either aerobic or anaerobic, again revealed predominance of enterococci with some Lact. bifidus. In this case of $E$. coli free intestine of natural state without artificial procedure, such as oral streptomycin, an attempt to reestablish the residency by the former resident strain also failed, after its appearance of a week's duration.

H. Effect of Lact. bifidus on the resident strain

Lact. bifidus is generally considered as forming a normal intestinal flora of breast babies and having a protective role against enteral infection and a role in growth of the infant.

Antagonism between Lact. bifidus and E. coli in test tube has been proved by some investigators. Attempts have been made to decrease the enteral infection in bottle babies by proliferating Lact. bifidus in their intestine, and recently a good results has been obtained by adding $\beta$-lactose and bifidus factor in the formula. There are some reports of good result in infantile diarrhea by administering fresh Lact. bifidus preparation to the patients.

In bottle babies Lact. bifidus increases on the plate in its growth as long as it 
is orally given and returns to a previous state in growth as it is discontinued. One of our colleague observed an infection of pathogenic E. coli $\mathrm{O} 112$ during a long period of Lact. bifidus administration. It may be explained from a standpoint of intensity in persistence of pathogenic $E$. coli. And also it might be held in case of nonpathogenic $E$. coli. In other word, a relationship of Lact. bifidus and E. coli in the intestine would not be explained by a simple antagonism as shown in a test tube.

Daily dose of one gram of a fresh Lact. bifidus preparation $\left(114 \times 10^{6} / \mathrm{g}\right)$ was orally given for a month in two bottle babies and the growth of Lact. bifidus and gram negative bacilli were compared in percentage.

Case $\mathrm{G}$ showed an increase in growth of Lact. bifidus and a decreased growth of gram negative bacilli on the plate during the administration of Lact. bifidus and there presumably was an antagonism between Lact. bifidus and E. coli (Table 1). However, there was no effect on a resident strain, C 253 (Fig. 10, Table 1).

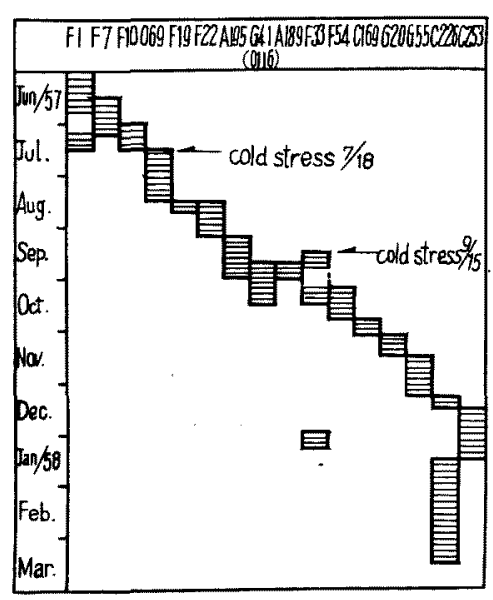

Fig. 9 Result on case F.

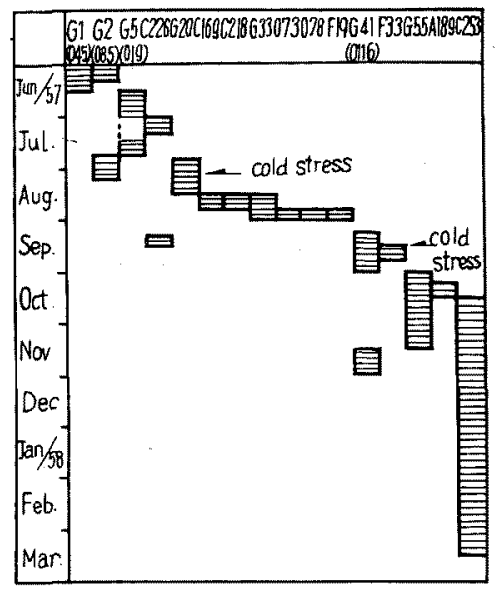

Fig. 10 Result on case G.

In case $\mathrm{F}$, on the other hand, there was an increase in growth of gram negative bacilli during Lact. bifidus administration and in regard to the resident strain, C 253 strain was replaced by C 226 strain during the last two weeks of this study. This change of the resident strain, however, would not be considered as being affected by Lact. bifidus, since gram negative bacilli, rather, increased in growth on the plate and two weeks lapsed since the first administration of Lact. bifidus.

These results proved there was no effect on the resident strain during administration of Lact. bifidus for a long period and there would be no difference between pathogenic and nonpathogenic E. coli in regard to their persistency in the intestine. 
Table 1

Effect of Lact. bifidus on Resident Strains (percentage)

\begin{tabular}{|c|c|c|c|c|c|c|c|c|c|c|c|c|}
\hline \multicolumn{13}{|c|}{$\mathrm{D} a \mathrm{t} e$} \\
\hline Case & $\begin{array}{l}\text { Micro- } \\
\text { organ. }\end{array}$ & $12 / 27$ & 28 & 30 & $1 / 2$ & 6 & 9 & 13 & 16 & 20 & 24 & 27 \\
\hline \multirow{5}{*}{$\mathrm{G}$} & Bif. & 0 & 2.2 & 0 & 66.0 & 2.4 & 7.3 & 22.9 & 13.1 & 31.6 & 32.0 & $22: 3$ \\
\hline & $+B$ & 0 & 14.3 & 0 & 0 & 0 & 0 & 0 & 0 & 0 & 0 & 0 \\
\hline & $-B$ & 93.9 & 82.4 & 92.6 & 24.1 & 4.8 & 26.4 & 17.6 & 63.1 & 28.1 & 16.0 & 26.5 \\
\hline & $\mathrm{C}$ & 6.1 & 1.1 & 7.4 & 9.9 & 92.8 & 66.3 & 57.5 & 23.8 & 40.3 & 52.0 & 51.2 \\
\hline & Resid. & C 253 & $\mathrm{C} 253$ & C 253 & C 253 & C 253 & C 253 & C 253 & C 253 & C 253 & $\mathrm{C} 253$ & $\mathrm{C} 253$ \\
\hline \multirow{5}{*}{$\mathrm{F}$} & Bif. & 2.8 & 1.4 & 0 & 93.0 & 30.0 & 17.0 & 10.0 & 1.9 & 26.3 & 55.1 & 4.4 \\
\hline & $+B$ & 0 & 0 & 0 & 0 & 0 & 0 & 0 & 0 & 0 & 0 & 0 \\
\hline & $-\mathbf{B}$ & 1.5 & 1.5 & 4.7 & 2.0 & 14.4 & 76.0 & 34.2 & 59.2 & 26.3 & 40.3 & 85.3 \\
\hline & $\mathrm{C}$ & 95.7 & 97.1 & 95.3 & 5.0 & 55.6 & 7.0 & 55.8 & 38.9 & 47.4 & 4.6 & 10.3 \\
\hline & Resid. & C 253 & C 253 & C 253 & $\mathrm{C} 253$ & C 253 & C 253 & C 253 & C 226 & C 226 & C 226 & C 226 \\
\hline
\end{tabular}

Bif. : Lact. bifidus, +B: Gram (+) bacilli, $-\mathrm{B}:$ Gram (-) bacilli, C: Enterococci, Resid.: Resident strain of $E$. coli.

I. Effect of so-called " cold caught in sleep"

In summer season infants or young children tend to expose their chests or abdomens, taking off cloths or blankets in sleep and catch cold often associated with diarrhea.

Two cases, $F$ and $G$, were followed to study the effect of exposure during sleep on resident strains and clinical symptoms. Case $F$ was asleep exposing chest and abdomen from 2.00 to $5.00 \mathrm{a}$. m. on $7 / 18 / 57$. Room temperature was $24^{\circ} \mathrm{C}$. No clinical symptoms or change in persistency of the resident strain $\mathrm{O} 69$ were noted. From 1.00 to 6.00 a. $\mathrm{m}$. on $9 / 15 / 57$ again a similar state was found. Room temperature was 20 to $22^{\circ} \mathrm{C}$. Slight nasal discharge was noted the following morning but a resident strain, A 195, was not affected.

Case G: Two occasions of similar state were found on $8 / 2$ and $9 / 15 / 57$. As seen in Fig. 10, in either case, there was no effect on the resident strain as well as in case F.

\section{DISCUSSION}

Through these observations on the resident strains of intestinal $E$. coli it would be said there is a relationship between the period of persistence and the season.

Resident strains in adults were reported by other investigators to persist as long as six months or a year and no one has proved the seasonal influence on the resident strains.

In this study of the resident strains in infants it is evident that there is no 
longer than three or four months of persistency and there is seasonal influence on the period of persistency of the resident strains.

As mentioned above, seven cases in this study had resident strains which persisted for relatively long periods, such as three or four months from November or December to following April or May. From rainy season to fall there was evidently a tendency for replacement of a resident strain by another strain, with a shorter period of persistency, such as one or one and a half months, as if being a transient strain.

Lact. bifidus predominates in normal intestinal flora of breast babies and is considered to be protecting against diarrheal attack or having a role in the growth of infants. Some investigators have reported the effect of oral Lact. bifidus in the case of diarrhea of bottle babies replacing the intestinal flora.

Tracing the intestinal flora of breast babies an investigator found the seasonal change of the intestinal flora. Lact. bifidus predominated in cold or cool season and was the opposite in summer season. He assumed there is a state of imbalance in intestinal flora as a cause of many occasions of infantile diarrhea in summer season.

Besides the biosynthesis of vitamins, etc, the role of intestinal $E$. coli in bottle babies remains open to question. There are some evidence which suggest a protective role of intestinal E. coli, in some way, against enteral infections. For example, in animal experiment when the intestinal flora is disturbed by oral streptomycin, the mice are susceptible to salmonella infection. From a hemoagglutinin study an investigator presumed an ecology of the intestinal E. coli plays a protective role against diarrheal attack.

These facts lead me to assume that the intestinal $E$. coli may protect, in some way, against enteral infection as far as their "balances" are kept in the intestinal flora.

Significant effects of chemotherapy or antibiotics and advancement of general hygine and knowledge of nursing have recently revealed a marked decrease in mortality due to gastroenteritis of infants. On the other hand, we have occasionally noted diarrhea cases aggravated by chemotherapy or antibiotics, which may be explained as due to change of the intestinal flora resulting from such therapy.

Supposing that intestinal $E$. coli acts as a protective lining of the intestinal mucosa, particularly in the colon, we may compare the role of $E$. coli with that of weeds striking roots on the bank. We may imagine a stream of intestinal content flowing between banks protected with weeds, in other word, mucosa protected with resident strain of $E$. coli.

Change of the resident strain of $E$. coli from a failure of symbiosis of resident 
strains and hosts caused by many stresses, such as bacterial or viral infections, either enteral or parenteral, change of diet or environment, and superinfection due to antibiotics therapy. At such times when changes occur in resident strains the infants have labil state of the intestinal mucosa, and they are susceptible to diarrhea. The fewer incidence of diarrheal attacks in adults may be explained by longer persistency of the resident strains.

On the contrary, the greater incidence of diarrhea in bottle babies, especially in summer; may partly be explained as due to relatively short persistency of the resident strain. Frequent incidence of parenteral diarrhea would be placed under same consideration.

Frequency of parenteral diarrhea has been reported to be 5 to $42 \%$ of infantile diarrhea by various investigators. In fact, compared with other causes, such as failure of feeding, parenteral infection is frequent cause of infantile diarrhea. Steuger described parenteral diarrhea induced by an experimental otitis media in a puppy. As assumed above, in changing resident strains of intestinal $E$. coli a labil state of intestinal mucosa, namely, susceptibility to diarrhea, would be resulted. A couple of days after vaccination against small pox there was a temporary disappearance of less growth of $E$. coli on the plate followed by transition of the resident strains in three of four cases. Although there was not such a temporary phenomenon on the plate in the case of BCG vaccination, the resident strains were affected by it also.

In the case of parenteral infection, breast babies have Lact. bifidus less prominently in intestinal flora although they have no diarrhea, and on occasion of diarrhea, Lact. bifidus loss predominance in intestinal flora. In this study, he concluded that Lact. bifidus prevents the occurence or the aggravation of diarrhea, by its predominance in intestinal flora of breast babies. Accordingly, the change of intestinal flora due to parenteral infection would result in a state of susceptibility to diarrhea.

Vaccination against small pox or BCG vaccination, as viral or bacterial infection, would affect the symbiosis of $E$. coli and host and be followed by change of resident strains or labil state of intestinal mucosa. There, however, should be some additional factors such as diet or state of constitution to manifest diarrhea in those conditions.

Although no definite correlation was found between diarrhea and transition of resident strains, as seen in many reports, the cases in this study having a relatively long duration of diarrhea were accompanied by change of resident strains.

Change of diet or environment, such as the first feeding of cereal or vegetable, showed an effect on resident strains. Sears described the effect of environment, such as a trip, on resident strains. In cases $\mathrm{A}$ and $\mathrm{B}$ there were transitions of resident strains without diarrhea following removal from the infant-home and likewise in case 
$\mathrm{C}$ with only a half day's outing. Change of resident strains would result in a lability of intestinal mucosa, however, this alone should not be sufficient to cause diarrhea and there would need to be some additional factors, such as parenteral infection to develop diarrhea.

Identical twins nursed under the same environment have no similarity in regard to intestinal flora of $E$. coli. Inoculation of pertussis vacccine had no effect on resident strains in case $B$.

Explanation of persistency of intestinal $E$. coli still remains questionable. A large amount of a former resident strain was orally given to case $C$ having presumably $E$. coli free intestine, however, it gradually disappeared in a week. Itoga in our department established a long persistency of a given strain of $E$. coli labelled "Streptomycin resistent" in new born infants or in young infants treated by oral streptomycin.

From these facts, of course, the factors of $E$. coli may not be denied in regard to persistency of resident strain. There, however, would be rather predominant factors in the host, such as maturity of intestinal mucosa, age difference, etc.

One of our colleague had an experience to observe an invasion of pathogenic E. coli $\mathrm{O} 112$ during treatment of Lact. bifidus, which was assumed as probably due to the intensity of the persistency of pathogenic E. coli. However, oral administration of Lact. bifidus for a month to bottle babies revealed no effect on resident strain. Thus in regard to persistency of intestinal $E$. coli and Lact. bifidus, factors between $E$. coli and host may be superior to antagonism of $E$. coli and Lact. bifidus.

Resident strains were not affected by exposure of body during sleep on four occasions in two cases, and there was no occasion of diarrhea. These results may lead to a conclusion that a symbiosis of $E$. coli and host has not been affected by cold stress itself, hence no labil state of intestinal mucosa is brought about. Accordingly, there would need to be an additional parenteral infection to exposure to affect the symbiosis in causing a labil state of intestinal mucosa.

\section{SUMMARY}

1) Persistence of the resident strains of intestinal $E$. coli in artificial feeding infants has proved to be shorter compared to that of adults especially in summer season.

2) There was no similarity in identical twins in regard to intestinal flora of E. coli.

3) Change of room in the same house, slight case of so-called cold, exposure of body in sleep, surgical scarlet fever, chicken pox, infantile eczema, skin infection, mild case of diarrhea of a few day's duration and therapeutic dosis of penicillin, 
sulfa drugs, streptomycin, INH, successive administration of Lact. bifidus and inoculation of pertussis vaccine have no effect on the resident strains.

4) In cases of amoebic dysentery there were found no steady resident strains during infection. However, in other two cases invaded by pathogenic E. coli 055 during epidemic there was no effect on resident strains.

5) Resident strains were affected by change in infant-home, outing, change of diet, such as the first feeding of cereal or vegetable, diarrhea of comparatively long duration, vaccination against small pox, $B C G$ vaccination and parenteral infection on some occasions.

\section{ACKNOWLEDGEMENT}

The authors express thanks to Dr. R. Sakazaki, Department of Agriculture and Forestry, for denotion of Kauffmann's standard strains 01-0134. This study was partly supported by the government grant in aid for scientific researches.

\section{REFERENCES}

1. Sakazaki, R.: Intestinal Flora Survey, 1956. (in Japanese)

2. Sears, J.: J. Bact. 59: 203, 1950.

3. Sears, J.: J. Bact. 63: 47, 1952.

4. Sears, J*: J. Bact. $71: 370,1956$.

5. Horie, K. : J. Keio Med. Society, 27: 277, 1950. (in Japanese)

6. Kojima, M.: Keio J. Med. 1: 107, 1952.

7. Ito, Y.: The Journal of Japanese Association for Infectious Diseases, 26: 177, 1952. (in Japanese)

8. Itoga, G.: Acta Pediatrica Japonica, 56:95, 1952. (in Japanese)

9. Wallik, H.: J. Bact. 45: 121, 1943.

10. Dekita, K.: Acta Pediatrica Japonica, 61: 870, 1957. (in Japanese)

11. Kauffmann, F.: J. Imm. 57: 71, 1947.

12. Ushiba, D.: Clinical Gastro-enterology, $2: 115,1954$. (in Japanese)

13. Kobari, K.; The Journal of Japanese Association for Infectious Diseases, 30:553, 1956. (in Japanes)

14. Hirata, J.: Japanese Journal of Bact., $3: 55,1948$. (in Japanese)

15. Hirata, J.: Japanese Journal of Bact., $4: 81,1949$. (in Japanese)

16. Hirata, J.: Kitasato Experimental Med, 22: 171, 1949. (in Japanese)

17. Stulberg, C.: Ann. New York Academy of Sci., 66: 90, 1956.

18. Ushiba, D.: The Journal of the Japan Medical Association, 36:279, 1956. (in Japanese)

19. Steward, W.: JAMA, $139: 579,1949$.

20. Nagaki, S.: Nippon Rinsho, 14:581, 1956. (in Japanese)

21. Ushiba, D.: Japanese Journal of Bact., $9: 1069,1954$. (in Japanese)

22. Bohnhoff, M.: Proc. Soc. Exp. Biol. Med., 86: 132, 1954.

23. Hiro, Y.: Journal of Pediatric Practice, 20:12, 1957. (in Japanese)

24. Takatsu, T.: Internal Med. \& Ped., 3: 402, 1948. (in Japanese)

25. Morohashi, T.: Acta Pediatrica Japonica, 57: 753, 1953. (in Japanese)

26. Petnely, F.: Münch. M. Wochschr., 98: 263, 304, 1956.

27. Morohashi, T.: Japanese Journal of Ped., 9:385, 1956. (in Japanese)

28. Morohashi, T.: Japanese Journal of Ped., 9: 905, 1956. (in Japanese) 
29. Morohashi, T.: Japanese Journal of Ped., 11: 310, 1958. (in Japanese)

30. Adachi, T.: Unpublished.

31. Komatsu, K.: Acta Pediatrica Japonica, 58: 474, 1954. (in Japanese)

32. Robinson, E.: J. Ped., 41: 395, 1952.

33. Kojima, M.: Journal of Pediatric Practice, 15: 375, 1952. (in Japanese)

34. Vital statistics, 1954, Japan.

35. Yabuki, S.: Acta Pediatrica Japonica 58: 956, 1954. (in Japanese)

36. Schreier, K.: Monschrf. Kinderheil., 101: 364, 1953.

37. Itoga, G.: Journal of Pediatric Practice, 14:710, 1951. (in Japanese)

38. Takuma, T.: Journal of Pediatric Practice, 11: 1, 1948. (in Japanese)

39. Takuma, T.: Journal of Pediatric Practice, 11: 85, 1948. (in Japanese)

40. Asami, K.: Journal of Pediatric Practice, 20:923, 1957. (in Japanese)

41. Steuger, C.: Z. Kinderheil., 67: 639, 1950.

42. Chapmann, G.: J. Bact., 53: 504, 1947.

43. Chapmann, G.: Am. J. Pub. Health, 41 : 1381, 1951.

44. Tsuchiya, H.: The Journal of the Japanes Association for Infectious Diseases, $26: 39,1952$. (in Japanese)

45. Nakao, S. Japanese Journal of Pediatrics, $56: 71,78,117,1952$. (in Japanese)

46. Itoga, G.: Keio J. Med., 1: 69, 1952. 